\title{
Bovine Spongiform Encephalopathy Induces Misfolding of Alleged Prion-Resistant Species Cellular Prion Protein without Altering Its Pathobiological Features
}

\author{
Enric Vidal, ${ }^{3}$ Natalia Fernández-Borges, ${ }^{1}$ Belén Pintado, ${ }^{4}$ Montserrat Ordóñez, ${ }^{3}$ Mercedes Márquez, ${ }^{6}$ \\ Dolors Fondevila, ${ }^{5,6}$ Juan María Torres, ${ }^{7}$ Martí Pumarola, ${ }^{5,6}$ and Joaquín Castilla ${ }^{1,2}$ \\ ${ }^{1}$ CIC bioGUNE, 48160 Derio, Bizkaia, Spain, ${ }^{2}$ IKERBASQUE, Basque Foundation for Science, 48011 Bilbao, Bizkaia, Spain, ${ }^{3}$ Centre de Recerca en Sanitat \\ Animal, Campus de la Universitat Autònoma de Barcelona (UAB)-IRTA, 08193 Bellaterra, Barcelona, Spain, ${ }^{4}$ Centro Nacional de Biotecnología, Campus de \\ Cantoblanco, 28049 Cantoblanco, Madrid, Spain, ${ }^{5}$ Department of Animal Medicine and Surgery, Veterinary Faculty, UAB, 08193 Bellaterra (Cerdanyola del \\ Vallès), Barcelona, Spain, ${ }^{6}$ Murine Pathology Unit, Centre de Biotecnologia Animal i Teràpia Gènica, UAB, 08193 Bellaterra (Cerdanyola del Vallès), \\ Barcelona, Spain, and ${ }^{7}$ Centro de Investigación en Sanidad Animal-Instituto Nacional de Investigación y Tecnología Agraria y Alimentaria, 28130 \\ Valdeolmos, Madrid, Spain
}

Bovine spongiform encephalopathy (BSE) prions were responsible for an unforeseen epizootic in cattle which had a vast social, economic, and public health impact. This was primarily because BSE prions were found to be transmissible to humans. Other species were also susceptible to BSE either by natural infection (e.g., felids, caprids) or in experimental settings (e.g., sheep, mice). However, certain species closely related to humans, such as canids and leporids, were apparently resistant to BSE. In vitro prion amplification techniques (saPMCA) were used to successfully misfold the cellular prion protein $\left(\operatorname{PrP}^{c}\right)$ of these allegedly resistant species into a BSE-type prion protein. The biochemical and biological properties of the new prions generated in vitro after seeding rabbit and dog brain homogenates with classical BSE were studied. Pathobiological features of the resultant prion strains were determined after their inoculation into transgenic mice expressing bovine and human $\operatorname{PrP}^{\mathrm{C}}$. Strain characteristics of the in vitro-adapted rabbit and dog BSE agent remained invariable with respect to the original cattle BSE prion, suggesting that the naturally low susceptibility of rabbits and dogs to prion infections should not alter their zoonotic potential if these animals became infected with BSE. This study provides a sound basis for risk assessment regarding prion diseases in purportedly resistant species.

\section{Introduction}

Bovine spongiform encephalopathy (BSE) was first described in cattle in 1985 (Wells et al., 1987) and became a major public health concern when evidence linked it to variant CreutzfeldtJakob disease in humans (Bruce et al., 1997; Hill et al., 1997). Unlike other animal prion diseases, BSE has transmitted naturally to humans and also to other domestic species including goats (Eloit et al., 2005), cats (Aldhous, 1990; Wyatt et al., 1991), zoological-kept felidae (Willoughby et al., 1992; Lezmi et al., 2003; Bencsik et al., 2009; Eiden et al., 2010), and ruminants

Received Jan. 18, 2013; revised March 7, 2013; accepted March 23, 2013.

Author contributions: E.V., N.F.-B., and J.C. designed research; E.V., N.F.-B., B.P., M.O., M.M., D.F., and J.C. performed research; E.V., N.F.-B., B.P., and J.C. contributed unpublished reagents/analytic tools; E.V., N.F.-B., B.P., M.O., M.M., D.F., J.M.T., M.P., and J.C. analyzed data; E.V. and J.C. wrote the paper.

This work was financially supported by two national grants from Spain (AGL2009-11553-C02-01 and AGL200805296-C02), Basque Government Grant PI2010-18, and Etortek Research Programs 2011/2013. We thank the IKERBasque Foundation for their support. We thank CIC bioGUNE, Sierra Espinar, Marta Valle, Mariano Moreno, and Paola Marco for the providing the vivarium and maintenance; the CReSA Biocontainment Unit staff for care and maintenance of the animals; Tomás Mayoral for the bovine spongiform encephalopathy brain tissue samples; and Mark Daeglish for his critical revision of the paper.

The authors declare no competing financial interests.

Correspondence should be addressed to Dr. Joaquín Castilla, CIC bioGUNE, Parque tecnológico de Bizkaia, Derio 48160, Bizkaia, Spain. E-mail: castilla@joaquincastilla.com.

DOI:10.1523/JNEUROSCI.0244-13.2013

Copyright $\odot 2013$ the authors $\quad 0270-6474 / 13 / 337778-09 \$ 15.00 / 0$
(Kirkwood and Cunningham, 1994). Experimentally, sheep are susceptible to BSE (Foster et al., 1993; Bellworthy et al., 2008) as are many laboratory animals including primates, pigs, mice, and guinea pigs (Fraser et al., 1988; Lasmezas et al., 1996; Wells et al., 2003; Castilla et al., 2004; Konold et al., 2009; Safar et al., 2011).

Most BSE cases diagnosed in cattle have been classified as classical BSE, which was believed to be caused by a single stable agent (Wells and Wilesmith, 1995). BSE exhibits a unique biochemical "signature", which has solely been associated with this particular prion strain, has been observed in the vast majority of BSE cases in cattle and is maintained when transmitted to other susceptible species (Collinge et al., 1996; Stack et al., 2002; Biacabe et al., 2004).

Even though BSE has crossed many transmission barriers, other species which have presumably been exposed to BSE prions have not been documented to succumb to prion disease. Among these are the members of the canidae and leporidae families (Gibbs and Gajdusek, 1973; Barlow and Rennie, 1976; Vorberg et al., 2003). The lack of literature in these species with respect to natural or experimental TSE transmissions supported their categorization as purportedly prion-resistant. However, recently developed in vitro prion amplification techniques, such as protein misfolding cyclic amplification (PMCA) (Saborio et al., 2001) 
and its variants (Castilla et al., 2006), are allowing reclassification of the strength of certain species transmission barriers (Fernandez-Borges et al., 2009; Chianini et al., 2012). The normal cellular prion protein $\left(\operatorname{PrP}^{\mathrm{C}}\right)$ from these purportedly resistant species can be successfully misfolded in vitro. However, it is essential to determine whether these novel abnormal prions are capable of inducing disease and whether their strain properties are maintained or not after passage through a supposedly resistant species. Due to its ability to infect humans, prediction of the behavior of BSE in purportedly resistant species that are either consumed by or in close contact with humans is vital for risk assessment. The design of experiments involving the natural, long-lived hosts is frequently unaffordable. Therefore, the use of repeated passages of intracerebral inoculation of transgenic mouse models (overexpressing the $\operatorname{PrP}^{\mathrm{C}}$ of the species under investigation) are used to overcome these limitations (Castilla et al., 2004; Sigurdson et al., 2006). Furthermore, an in vitro approach in which brain homogenates from the chosen species under investigation are submitted to several rounds of amplification by PMCA greatly increases transmission efficiency (Castilla et al., 2008; Chianini et al., 2012).

In this study, we analyzed the biochemical and biological properties of new prions generated in vitro after seeding rabbit and dog brain homogenates with classical BSE. Pathobiological features of the resultant prion strains were studied after their inoculation in transgenic mice expressing bovine and human $\mathrm{PrP}^{\mathrm{C}}$. Strain characteristics of the in vitro-adapted rabbit and dog BSE agent remained invariable with respect to the original cattle BSE prion, suggesting that the naturally low susceptibility of rabbits and apparently of dogs to prion infections (Polymenidou et al., 2008; Kurt et al., 2011) should not alter their zoonotic potential if these animals became infected with BSE. This study provides a sound basis for risk assessment regarding prion diseases in purportedly resistant species.

\section{Materials and Methods}

Inocula preparation for in vitro prion replication studies. Brain homogenates $\left(10^{-1}\right.$ in PBS) for use as seeds were prepared by manual potter from a brain of a clinically affected BSE-positive bovid (TSE/08/59) supplied by the Veterinary Laboratory Agency (New Haw, Addlestone, Surrey, UK). The titer of this inoculum was $\sim 10^{8}$ ID50 units per gram of bovine brainstem, as determined in the boTg110 mouse line (Castilla et al., 2003).

Generation of in vitro $\mathrm{Pr} \mathrm{P}^{\text {res }}$ by serial automated $P M C A$. The in vitro prion replication, including the $\operatorname{PrP}^{\mathrm{Sc}}$ detection of amplified samples, was performed as described previously with minor modifications (Saá et al., 2006). Briefly, $5 \mu \mathrm{l}$ aliquots of $10 \%$, and $50 \%$ in the case of the dog, brain homogenate from animals infected by BSE were diluted in $50 \mu \mathrm{l}$ of $10 \%$ normal rabbit and dog brain homogenates and loaded onto $0.2 \mathrm{ml}$ PCR tubes. Rabbit and dog brains used for substrate were previously perfused using PBS $+5 \mathrm{~mm}$ EDTA. The blood-depleted brains were frozen immediately before preparing the $10 \%$ brain homogenates (PBS $+\mathrm{NaCl} 1 \%+1 \%$ Triton X-100). Tubes were positioned on an adaptor placed on the plate holder of a microsonicator (Misonix, Model 4000 ) and subjected to cycles of $30 \mathrm{~min}$ incubation at $38^{\circ} \mathrm{C}$ followed by a $20 \mathrm{~s}$ pulse of sonication at potency 80 . Samples were incubated in the water bath of the sonicator without shaking. Serial rounds of PMCA consisted of $48 \mathrm{~h}$ of standard PMCA followed by serial in vitro 1:10 passages in fresh rabbit brain substrate. An equivalent number of unseeded tubes containing the corresponding brain substrate were subjected to the same number of rounds of serial automated PMCA (saPMCA) to control cross-contamination and/or the generation of spontaneous $\mathrm{PrP}^{\mathrm{res}}$. The detailed protocol for PMCA, including reagents, solutions, and troubleshooting, were previously published (Saá et al., 2005).

Inocula preparation for in vivo prion replication studies. Inocula for second passages where prepared by homogenizing the harvested CNS (spinal cord and olfactory bulb) material from infected first passage mice 1:10 (w/v) with sterile PBS. The homogenates where filtered through a surgical gauze. Homogenate from one mouse brain from the first passage was used to prepare the inocula, the mice used had $365 \mathrm{~d}$ postinoculation (dpi) in the case of BSE-DoPrP ${ }^{\text {res }}$ and 312 in the case of BSE-RaPrP ${ }^{\text {res }}$.

Biochemical characterization of in vitro-generated and in vivo-generated prion strains. The standard procedure to digest $\mathrm{PrP}^{\mathrm{Sc}}$ was performed following the basic conditions described previously (Castilla et al., 2005a). Briefly, PMCA samples were digested using $85-200 \mu \mathrm{g} / \mathrm{ml}$ protease $\mathrm{K}(\mathrm{PK})$ during $1 \mathrm{~h}$ at $42^{\circ} \mathrm{C}$ with shaking ( $\left.450 \mathrm{rpm}\right)$. Digestion was stopped by adding electrophoresis loading buffer and the samples were analyzed by Western blotting.

tgBov and tgHum mice inoculation. The bovine PRNP expression mouse model boTg110 (tgBov) was established and characterized as described previously (Castilla et al., 2003; Castilla et al., 2005b; Espinosa et al., 2007). Briefly, these mice express bovine $\operatorname{PrP}^{\mathrm{C}}$ under the murine PRNP promoter in a murine $\operatorname{PrP}^{0 / 0}$ background. Bovine $\operatorname{PrP}^{\mathrm{C}}$ expression levels in this mouse line are stated to be eightfold higher than the $\operatorname{PrP}^{\mathrm{C}}$ levels found in cattle brain homogenates. As a model to assess the theoretical human susceptibility, the model Tg340 (tgHum), which expresses human PRNP (4-fold higher than in human brain) with a methionine at codon 129 (Met129) also on a murine PRNP-null background, was used (Padilla et al., 2011).

Each 6- to 8-week-old mouse received an intracerebral inoculation (20 $\mu \mathrm{l}$ ) through the parietal bone using a $50 \mu$ l SGC precision syringe, a 25 gauge needle, and a repeatability adaptor. During the inoculation procedure, the mice were kept under deep gaseous anesthesia (isoflurane). A subcutaneous dose of buprenorphine was administered before awakening to minimize postinoculation pain.

Mice were kept under controlled conditions at a room temperature of $21-22^{\circ} \mathrm{C}, 12 \mathrm{~h}$ light/dark cycle and $60 \%$ relative humidity. Cages were in HEPA-filtered (both air inflow and extraction) ventilated racks. The mice were fed ad libitum. To evaluate transmissible spongiform encephalopathy (TSE)-related clinical signs, mice were observed daily and their neurological status was assessed twice a week. The presence of three signs of neurological dysfunction (using 10 different criteria) (Scott et al., 1989) was necessary for a mouse to score positive for prion disease. Only female mice were used to avoid male aggression.

In vitro inocula (BSE-RabPrP ${ }^{\text {res }}$ and $\mathrm{BSE}-\mathrm{DogPrP} \mathrm{P}^{\text {res }}$ ) were subjected to at least 15 rounds of saPMCA (a $10^{-15}$ dilution of the initial seed) after the first evidence of in vitro crossing of the species barrier (Fig. 1).

The groups were designed as follows: for the boTg110 model 10 animals were inoculated with cattle BSE on first passage and 9 on second passage; 16 animals were inoculated with BSE-RabPrP ${ }^{\text {res }}$ on first passage and 12 on second; 17 animals were inoculated with BSE-DogPrP ${ }^{\text {res }}$ on first passage and 13 on second, and finally, as a negative control 12 mice where inoculated with brain homogenate from a clinically healthy, BSEnegative cow. For the $\operatorname{Tg} 340$ (Met129) model, 10 animals were inoculated with cattle-BSE, 9 with BSE-RabPrP res , and 6 with BSE-DogPrP ${ }^{\text {res }}$.

Ethics statement. The procedures involving animals were approved by the animal experimentation ethics committee of the Autonomous University of Barcelona (Reference No. 585-3487) in agreement with Article 28, sections (a), (b), (c), and (d) of the "Real Decreto 214/1997 de 30 de Julio" and the European Directive 86/609/CEE and the European council Guidelines included in the European Convention for the Protection of Vertebrate Animals used for Experimental and Other Scientific Purposes.

Sample processing and general procedures. Immediately after mice were killed (by intraperitoneal overdose of pentobarbital and decapitation) the brain was extracted and placed into $10 \%$ phosphate buffered formalin. Transversal sections of the brain were obtained at the level of the optic chiasm, piriform cortex, and medulla oblongata. Samples were dehydrated through increasing alcohol concentrations and xylene before embedding in paraffin wax. Four-micrometer sections were cut and mounted on glass microscope slides and stained with hematoxylin and eosin for morphological evaluation. Further slides were mounted in 3-trietoxysililpropilamine-coated glass slides for immunohistochemical studies.

Immunohistochemistry. Immunohistochemistry (IHC) against $\operatorname{PrP}^{\mathrm{d}}$ was performed as previously described (Siso et al., 2004). Briefly, depar- 
Rounds (R1-R10) of serial autom ated PMCA using rabbit, dog and cattle brain homogenate as substrates.

\begin{tabular}{|c|c|c|c|c|c|c|c|c|c|c|c|c|c|}
\hline Seed & $\%$ inoculum & Substrate & Dilution & R1 & R2 & R3 & R4 & R5 & R6 & R7 & R8 & R9 & R10 \\
\hline BSE & $10 \%$ & Rabbit & 1:10 & & & & & & & & & & \\
\hline \multicolumn{2}{|c|}{ Unseeded } & Rabbit & $1: 10$ & & & & & & & & & & \\
\hline BSE & $10 \%$ & Dog & 1:10 & & & & & & & & & & \\
\hline BSE & $50 \%$ & Dog & $1: 2$ & & & & & & & & & & \\
\hline \multicolumn{2}{|c|}{ Unseeded } & Dog & 1:10 & & & & & & & & & & \\
\hline BSE & $10 \%$ & Cattle & 1:10 & & & & & & & & & & \\
\hline \multicolumn{2}{|c|}{ Unseeded } & Cattle & 1:10 & & & & & & & & & & \\
\hline
\end{tabular}

The gray scale in the boxes indicates the $\%$ of positive tubes (showing PK resistant rabbit, dog and cattle Prpres) out of the total number of tubes sonicated $(n=4)$.

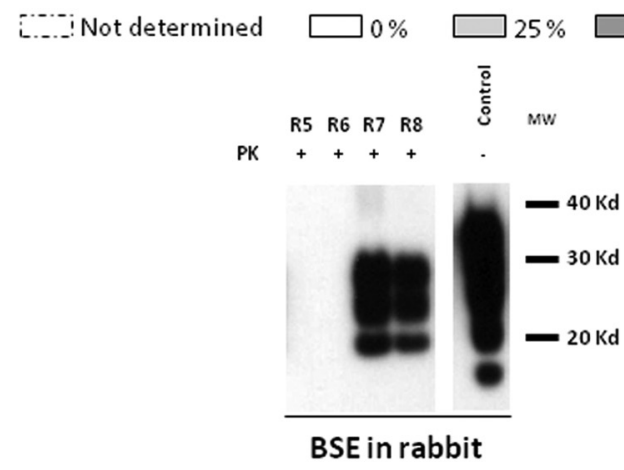

$50 \% \square 75 \% \square 100 \%$

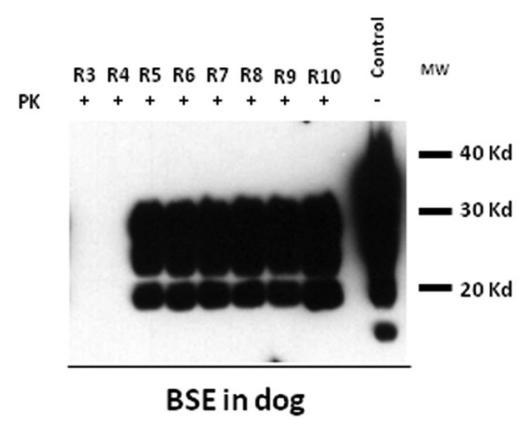

Figure 1. In vitro amplification experiments. Rounds (R1-R10) of serial automated PMCA using rabbit, dog, and cattle brain homogenate as substrate. Note dog brain inocula are at 10 and $50 \%$. Serial rounds (R5-R8 for rabbit and R3-R10 for dog) were selected to show biochemical analyses of BSE seeded PrP res generated in vitro by saPMCA. Samples from one of four tubes subjected to saPMCA were digested with $100 \mu \mathrm{g} / \mathrm{ml}$ PK and analyzed by Western blot using monoclonal antibody D18. Control, Undigested cattle brain homogenate; R, round.

affinized sections were immersed in formic acid and boiled at low $\mathrm{pH}$ in a pressure cooker, with endogenous peroxidases blocked. After pretreatment with $\mathrm{PK}$, the sections were incubated overnight with primary anti-PrP mAb 6H4 antibody (1:2000, kindly provided by Prionics AG), and finally, visualized using the Dako EnVision system and 3,3'diaminobenzidine as the chromogen substrate as per the manufacturer's instructions. As a background control, the primary antibody incubation was omitted. No labeling was observed in any of the control slides.

Semiquantification and data analysis. Semiquantification of the histopathological lesions and $\operatorname{PrP}^{\mathrm{d}}$ immunolabeling was performed. Subjective scores ranging from 0 (absence of spongiosis or immunolabeling) to 5 (maximum intensity of lesion or immunolabeling) were assigned to each brain area studied and profiles were constructed. Intermediate levels were (1) mild, (2) moderate, (3) marked, and (4) intense. Each area was investigated as a global region for the score.

The brain profiling approach consisted of a systematic screening of the different brain regions to obtain comparable data from the different prions used to challenge mice. A total of 15 different regions were chosen and semiquantitatively evaluated by eye as a whole for labeling intensity. The results were plotted on a graph that summarizes the distribution of lesions and $\operatorname{PrP}^{\mathrm{d}}$ throughout the brain. This allowed for comparison of the different groups studied.

For both parameters, results were plotted as a function of the anatomical area. Areas were ordered along the $x$-axis in an attempt to represent the caudorostral axis of the brain. This methodology was adapted from a previous study performed on BSE-infected cattle (Vidal et al., 2005). For statistical analysis, the Mann-Whitney $U$ test for nonparametric variables was applied $\left({ }^{\star} p<0.05\right.$ with $95 \%$ confidence interval, ${ }^{\star *} p<0.01$ with $99 \%$ confidence interval). Graphs were plotted using Microsoft Office 2007 Excel software.

\section{Results}

In vitro generation of rabbit and dog adapted BSE prions

We seeded normal rabbit and dog brain homogenates in vitro with cattle BSE brain homogenate before saPMCA in an attempt to study the ability to generate rabbit and dog adapted BSE PrP ${ }^{\text {res }}$ (BSE-RaPrP ${ }^{\text {res }}$ and BSE-DoPrP ${ }^{\text {res }}$, respectively). Although saPMCA is not a quantitative technique, rabbit $\operatorname{PrP}^{\mathrm{C}}$ appeared to be more susceptible to protein misfolding as BSE-seeded rabbit brain homogenate generated $\mathrm{PK}$ resistant $\mathrm{RaPrP}^{\text {res }}$ by round 7 (Fernández-Borges et al., 2009; Chianini et al., 2012) compared with $\operatorname{dog} \operatorname{PrP}^{\mathrm{C}}$ which showed higher resistance (Fig. 1). This impaired ability to convert $\operatorname{dog} \operatorname{PrP}^{\mathrm{C}}$ was consistent in all the seeds used (our unpublished observations) suggesting that in vitro propagation was impeded. Because the in vitro crossing of species barriers is a quasi-stochastic phenomenon, we modified the settings of saPMCA in an attempt to adapt it to the potentially most resistant species barrier known in mammals. Thus, dog brain homogenates were seeded with a larger amount of BSEpositive cattle brain material (50\% instead of the standard 10\%) and the dilutions were performed at 1:2(v/v) during subsequent rounds of PMCA. These changes enabled the cattle-dog transmission barrier to be overcome at round 5 (Fig. 1). Biochemical characterization, by Western blotting, of the in vitro generated 


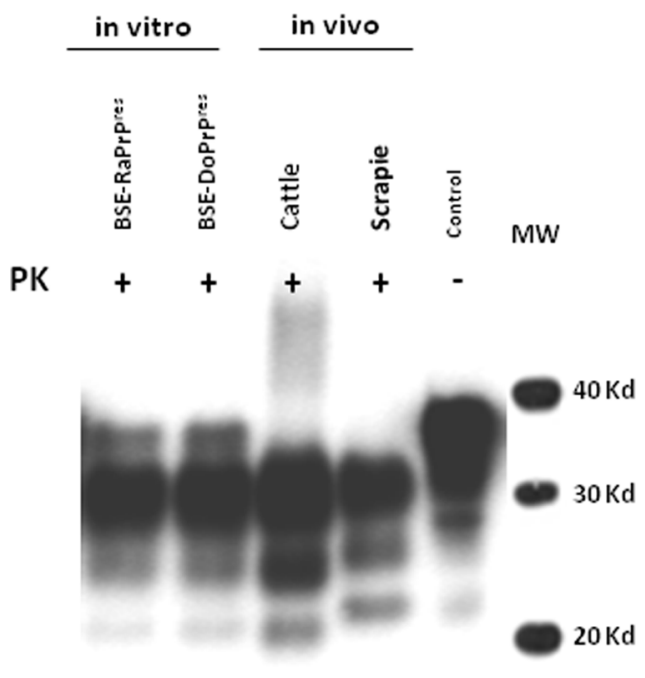

Figure 2. Biochemical analyses of BSE seeded PrP res generated in vitro by saPMCA using cattle, rabbit, and dog brain homogenates as substrates. Cattle, rabbit, and dog brain homogenates seeded with BSE-positive cattle brain homogenate were subjected to saPMCA. Seeded samples (BSE-BoPrP res, BSE-RaPrP res, and BSE-DoPrP res) from round 10 were digested with $100 \mu \mathrm{g} / \mathrm{ml} \mathrm{PK}$ and analyzed by Western blot using monoclonal antibody D18. The electrophoretic migration patterns in all the in vitro samples and the in vivo BSE-positive cattle sample used as positive control were indistinguishable. Scrapie was used as reference for determining the different electrophoretic migration patterns. Control, Undigested cattle brain homogenate.

Table 1. Attack rates and mean survival times ( \pm SEM) of inoculated tgBov mice

\begin{tabular}{|c|c|c|c|c|}
\hline & \multicolumn{2}{|l|}{ First passage } & \multicolumn{2}{|c|}{ Second passage } \\
\hline & Attack rate & $\begin{array}{l}\text { Survival time } \\
\text { (dpi) ( } \pm \text { SEM) }\end{array}$ & Attack rate & $\begin{array}{l}\text { Survival time } \\
\text { (dpi) ( } \pm \text { SEM) }\end{array}$ \\
\hline Cattle BSE & $10 / 10$ & $355( \pm 15)$ & $9 / 9$ & $348( \pm 11)$ \\
\hline BSE-RaPrP res & $16 / 16$ & $395( \pm 16)$ & $11 / 12^{a}$ & $339( \pm 8)$ \\
\hline BSE-DoPrp res & $17 / 17$ & $394( \pm 12)$ & $13 / 13$ & $274( \pm 9)^{b}$ \\
\hline Healthy cattle brain & 0/12 & $>500^{c}$ & ND & ND \\
\hline
\end{tabular}

ND, Not determined.

${ }^{a}$ One mouse was killed at 365 dpi and was IHC negative and showed no spongiform changes. This animal was not taken into account for incubation period calculations.

${ }^{b} 0$ ne animal was found dead at $96 \mathrm{dpi}$ and was Prp res positive in the brain. This animal was taken out as an outlier because the cause of death could not be determined due to autolysis.

'An end point for negative controls was set at $506 \mathrm{dpi}$, data from other experiments show that healthy brain homogenate inoculated tgBov mice can survive $>700$ dpi (not shown).

BSE-DoPrP ${ }^{\text {res }}$ showed a similar pattern compared with the cattle BSE homogenate used as seed (Fig. 2). Once the species barriers were initially overcome in vitro, the derived BSE-RaPrP ${ }^{\text {res }}$ and BSE-DoPrP ${ }^{\text {res }}$ products were further amplified efficiently in vitro (data not shown). We selected saPMCA products from BSE seeded normal rabbit and dog brain homogenates and cattle brain derived BSE to be used as challenge inocula. All samples were subjected to at least 15 rounds of saPMCA (a $10^{-15}$ dilution of the initial seed which, according to its infectious titer, ensured no residual infectivity was left) after the first evidence of in vitro crossing of the species barrier.

\section{Unaltered pathobiological BSE features after inoculation of rabbit, dog, and cattle adapted BSE prions in a bovine transgenic mouse model}

To assess the infectivity of the newly in vitro generated prions, transgenic mice overexpressing bovine $\operatorname{PrP}^{\mathrm{C}}$ (Castilla et al., 2003) were challenged intracerebrally. Brain homogenate from healthy, BSE-negative cattle was used as a negative control (Table 1).

A first passage through the transgenic mice of the cattle BSE and BSE- $\mathrm{RaPrP} \mathrm{P}^{\text {res }}$ or BSE-DoPrP ${ }^{\text {res }}$ inocula resulted in strikingly similar survival curves (Fig. 3) and no statistically significant differences were observed between the three inocula. The approximate difference in survival times of $40 \mathrm{~d}$ postinoculation (Table 1) might be a consequence of a low titer of the BSE-RaPrP ${ }^{\text {res }}$ and BSE-DoPrP ${ }^{\text {res }}$ samples amplified in vitro or because of a change of the prion strain after overcoming the cattle-rabbit and cattledog species barriers. A second passage through the transgenic mice was then performed to address this question. Upon this second passage, the incubation period of mice inoculated with cattle BSE was not statistically significantly different $(~ p=0.9296$, Mann-Whitney test) to the first passage, whereas the other two inocula showed a significant reduction of the incubation periods compared with their respective first passages $(p=0.006$ for BSE$\mathrm{RaPrP}^{\text {res }}$ and $p=0.000,005$ for BSE-DoPrP ${ }^{\text {res }}$, Mann-Whitney test). This could be interpreted as host adaptation process or as an increased titer compared with the in vitro generated inoculum. This reduction was especially greater for the $\mathrm{BSE}-\mathrm{DoPrP} \mathrm{P}^{\text {res }}$, which was significantly shorter compared with the incubation period of the second passage of cattle BSE inoculated mice ( $p=$ 0.0003, Mann-Whitney test). Shorter survival times than the original cattle BSE inocula have also been reported for sheeppassaged BSE (Espinosa et al., 2007). On the other hand, second passage BSE-RaPrP res showed no statistically significant differences in the incubation period compared with cattle BSE ( $p=$ 0.2207, Mann-Whitney test).

Brain homogenates from the sick mice were obtained and the molecular weights and glycosylation patterns of $\mathrm{PrP}^{\text {res }}$ after $\mathrm{PK}$ digestion were studied by Western blotting. No differences were observed between the $\mathrm{PrP}^{\text {res }}$ of BSE infected cattle and the prions recovered from inoculating tgBov mice with either cattle BSE and rabbit or dog in vitro amplified prions. On second passage, the biochemical profile also remained unaltered (Fig. 4).

We then examined microscopically the brains of the inoculated mice. Consistent spongiform changes were observed in all BSE inoculated animals consisting of variably sized vacuoles in the neuropil of the gray matter (Fig. 5). The distribution of the lesion intensity throughout the brain was assessed semiquantitatively and showed that the three inocula yielded a very similar lesion profile on the first passage (data not shown). Lesions were particularly intense in the medulla oblongata, cerebellar nuclei, mesencephalon, thalamus, and striatum with significantly less involvement of the neocortex, cerebellar cortex, and piriform cortex. The hippocampal formation also showed some degree of spongy change. The brain lesion profiles of the second passageinoculated animals remained unchanged compared with the first passage and also between the different inocula (Fig. 5); no significant differences were detected between the cattle BSE $\operatorname{tgBov}$ inoculated mice brain profiles and those of mice inoculated with $\mathrm{BSE}-\mathrm{DoPrP} \mathrm{P}^{\mathrm{res}}$ or BSE-RaPrP${ }^{\text {res }}$. However, the striatum $(\mathrm{S})$ of the animals inoculated with the BSE-DoPrP ${ }^{\text {res }}$ showed significantly less spongiform lesions and $\mathrm{PrP}^{\mathrm{d}}$ accumulation than the BSERabPrP ${ }^{\text {res }}$ or cattle BSE inoculated groups.

The immunolabeling patterns (monoclonal antibody 6H4) were consistent among the three differently challenged groups of mice and were mainly extracellular rounded plaque-like deposits of $\operatorname{PrP}^{\mathrm{d}}$. However, other patterns were observed also including fine punctuate to coarse granular, intraneuronal, perineuronal, and glial-associated (Fig. 5). The anatomical distribution of the $\mathrm{PrP}^{\mathrm{d}}$ deposition intensity was also semiquantitatively assessed and the profile obtained was considerably similar to that of the lesions. On the second passage, the brains from BSE-DoPrP ${ }^{\text {res }}$ inoculated $\operatorname{tgBov}$ mice showed less $\mathrm{PrP}^{\mathrm{d}}$ immunolabeling intensity in the cortices and hippocampus than mice from the other 
A

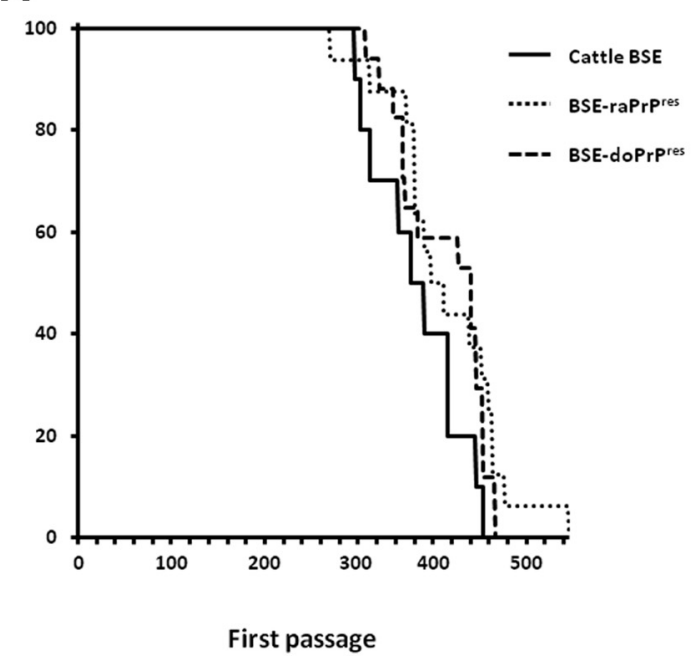

B

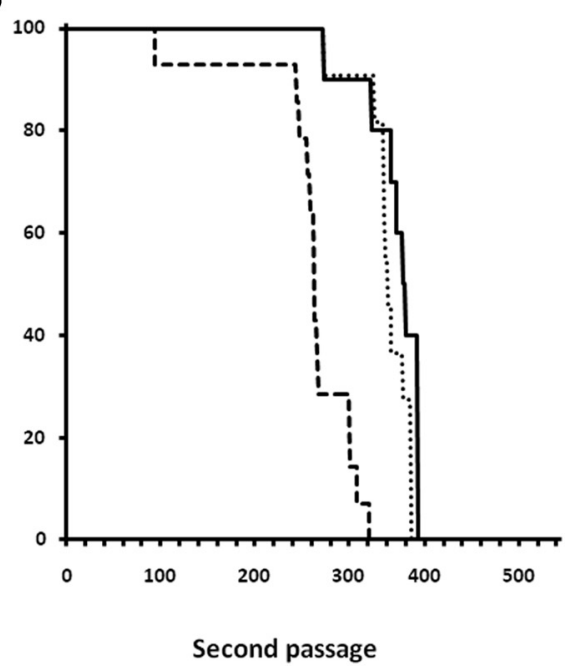

Figure 3. Survival Curves of cattle BSE, BSE-DoPrP ${ }^{\text {res }}$ and Ra-PrP res inoculated tgBov mice. $\boldsymbol{A}$, First passage; $\boldsymbol{B}$, second passage. In the survival curves, the vertical axis represents the percentage of live animals and the horizontal axis the days postinoculation.

groups, which could be explained by the shorter incubation period (data not shown). Despite this difference in intensity, the profiles from all groups were similar in shape. The lesion profile showed a consistently lower $\operatorname{PrP}^{\mathrm{d}}$ score in the striatum of BSE$\mathrm{DoPrP}{ }^{\text {res }}$ inoculated mice compared with the other two groups.

\section{Preserved ability of rabbit adapted BSE prions to infect a human transgenic mouse model}

Mice carrying the human PRNP gene were also inoculated intracerebrally with the in vitro generated BSE seeded products to assess their zoonotic potential. The cattle BSE inoculum did not result in disease in any of the animals (attack rate 0/10), a low infectivity rate that is consistent with published data on first passage of BSE in this model (Beringue et al., 2008; Padilla et al., 2011). Similarly, no animals inoculated with BSE-DoPrP ${ }^{\text {res }}$ succumbed to disease (0/6). However, 2 of 9 mice inoculated with $\mathrm{BSE}-\mathrm{RaPrP}{ }^{\text {res }}$ died at 560 and 699 dpi showing spongiform lesions and $\operatorname{PrP}^{\mathrm{d}}$ deposits by IHC (Fig. 6; Table 2). The remaining animals died at different dpi without showing TSE-like signs, except for those associated to aging, and all were negative in the three tests performed to confirm TSE diagnosis (spongiform changes, IHC for $\mathrm{PrP}^{\mathrm{d}}$, and Western blot for $\mathrm{PrP}^{\text {res }}$ ). Spongiform lesions were minimal in the TSE-positive transgenic mice and mixed with age-related spongiosis. $\mathrm{PrP}^{\mathrm{d}}$ deposits were observed only in the thalamus and consisted of small foci of coarse granular $\mathrm{PrP}^{\mathrm{d}}$ aggregates associated with the spongiosis. Overall, these results show that in vitro rabbit prions, likely enciphering a BSE strain, preserve the ability to infect humanized mice.

Several mice were found dead because of non-TSE-related causes but otherwise the animals were kept alive for their recognized lifespan (in the cattle BSE group up to $797 \mathrm{dpi}$, in the $\mathrm{BSE}-\mathrm{RaPrP}{ }^{\text {res }}$ group up to $704 \mathrm{dpi}$, and in the $\mathrm{BSE}-\mathrm{DoPrP} \mathrm{P}^{\text {res }}$ group up to $853 \mathrm{dpi}$ ).

\section{Discussion}

Prion diseases have been known for a long time, especially scrapie in sheep and goats, and some diseases affecting humans, including Kuru and Creutzfeldt-Jakob disease. Yet the occurrence and identification of the BSE epizootic was a remarkable milestone in the history of prion disease as cattle had never before been affected by TSE and so were presumed resistant. The recognition that BSE was zoonotic turned prion diseases of animals into a serious threat to public health, which resulted in an unprecedented crisis of confidence in consumers. Vast amounts of money were spent in numerous countries, not just to eliminate hundreds of thousands of infected animals, but also to establish radical changes related to disease control and surveillance, i.e., diagnostic tests, disposal of specified risk material, which could no longer be used in the food industry, etc. However, as prion diseases became the subject of profound scientific study, previously unknown prion strains have been discovered, many with unknown species susceptibilities and zoonotic potential. Thus, the susceptibility of different species to prions, particularly those that may come into close contact with humans, is a matter of continuous debate and study in the scientific community and great concern when determining health and safety policies.

Detailed study of naturally occurring prions is not enough to understand the behavior of these proteins in certain species. Before 1985, no one could have foreseen the massive cattle BSE epizootic. Hence, the scientific community is now particularly cautious when assessing the risk associated with host susceptibilities of various prions. Nevertheless, certain species display a limited or apparently null susceptibility to prion disease. Therefore, could one assume that such species would be resistant to all existing prion strains? If only one prion strain should be able to infect a new species, it might adapt to the new host and become easily transmissible. To address this we used all the tools available (i.e., in vitro amplification and transgenic mouse models) to evaluate the behavior of BSE prions in two historically considered prion disease resistant species: dogs and rabbits. BSE was chosen due to its zoonotic properties and because, as mentioned above, it is a promiscuous strain that has demonstrated infectivity in a wider range of species than most other prions. Even though these experimental conditions are far from modeling natural scenarios, they may enable us to predict the outcome of potential unforeseen species susceptibilities and epizootics as occurred with BSE (mad cow disease). During the last decade, in vitro replication studies endorsed PMCA as one of the most powerful technologies to overcome transmission barriers (Castilla et al., 2008; Green et al., 2008; Fernández-Borges and Castilla, 2010; Barria et al., 2011; Kurt et al., 2011; Yoshioka et al., 2011; Chianini et al., 2012). 
A

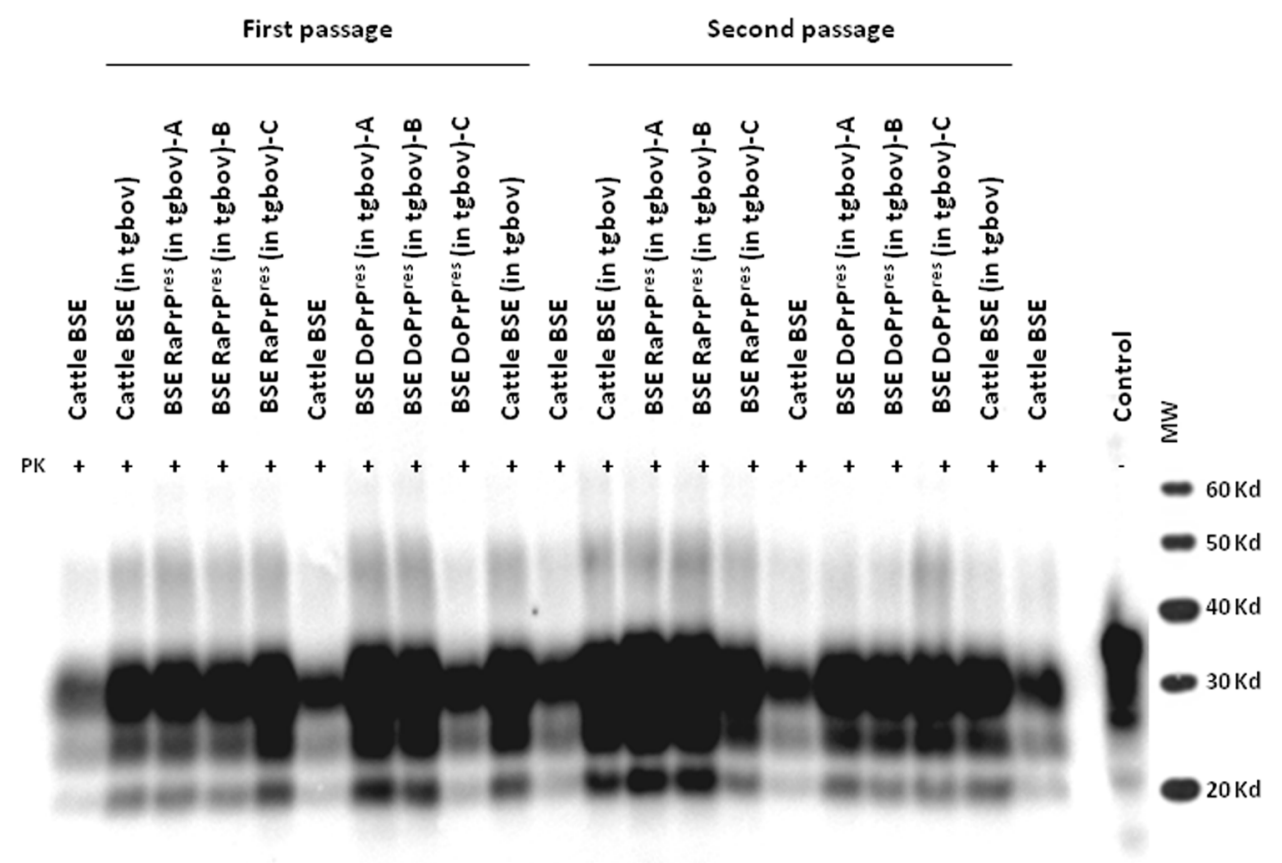

B

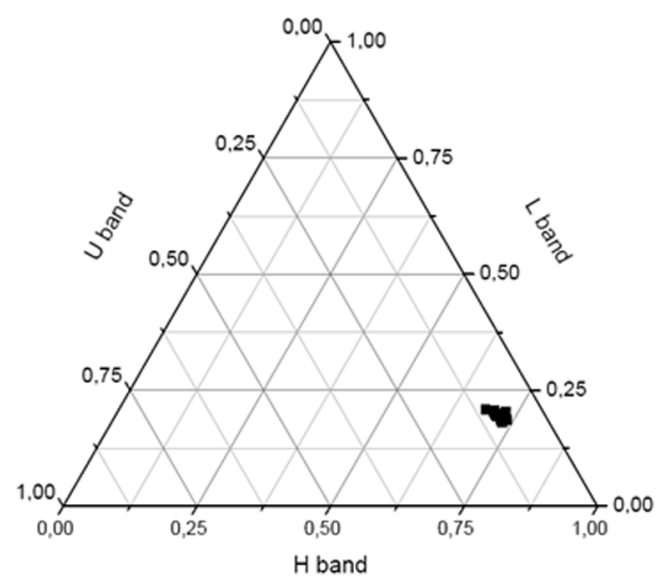

Figure 4. Comparative electrophoretic patterns. $A$, First and second passages of the different samples from tgBov mice (cattle BSE, BSE-DoPrP res, and Ra-PrP res) were compared with natural cattle BSE. The glycoform ratios and the molecular weights of the PrP res are all indistinguishable from cattle BSE. All samples were digested with $40 \mu \mathrm{g} / \mathrm{ml}$ PK and analyzed by Western blot using monoclonal antibody D18. Cattle BSE and cattle BSE (in tgBov) were loaded several times in the gel for comparative purposes. Three different mice of each group $(\boldsymbol{A}-\boldsymbol{C}$ ) are represented for each type of sample and passage used. Control, Cattle brain homogenate. $\boldsymbol{B}$, Triangular plot representing the glycoform proportions evaluated densitometrically from the above gel. Each axis represents the percentage of each band. H, Biglycosilated; L, monoglycosilated; U, unglycosilated. Notice that all wells show a remarkably similar band proportion.

Thus, dog and rabbit normal brain homogenates were seeded with BSE prions and submitted to in vitro amplification (saPMCA) to try to overcome the species transmission barrier. Interestingly, rabbit $\operatorname{PrP}^{\mathrm{C}}$ could be misfolded with relative ease by any of the prion strains used TSE (Barlow and Rennie, 1976; Fernández-Borges et al., 2009; Chianini et al., 2012). This was rather surprising since this species had, until then, been considered resistant to TSE (Barlow and Rennie, 1976; FernándezBorges et al., 2009; Chianini et al., 2012). However, dog brain homogenate could not be misfolded until the initial BSE prion seed concentration was raised considerably, and even with this modification only BSE was able to misfold $\operatorname{dog} \operatorname{PrP}^{\mathrm{C}}$, which suggested a strong resistance of this species to BSE.

Comparison of the original cattle BSE prions with those generated by seeding rabbit and dog brain homogenate with BSE followed by in vitro saPMCA demonstrated that the biochemical strain properties of BSE were maintained in the new species, i.e., glycoform proportion and molecular weight after PK digestion. This suggests that the BSE prion's conformation is reliably transmitted to new $\operatorname{PrP}^{\mathrm{C}}$ species in vitro. However, to ensure that the BSE strain's pathobiological properties was also transmitted, particularly those regarding infectivity and the ability to cross certain species barriers, an in vivo approach was mandatory. The transgenic mouse model expressing the bovine PRNP gene was chosen as it had previously demonstrated to reproduce reliably BSE strain features. This model was key in determining that BSE acquired a different behavior regarding the length of the incubation period upon its passage through sheep, while maintaining other strain features, such as Western blot electrophoretical profile, molecular weight, and PK resistance (Espinosa et al., 2007). As 

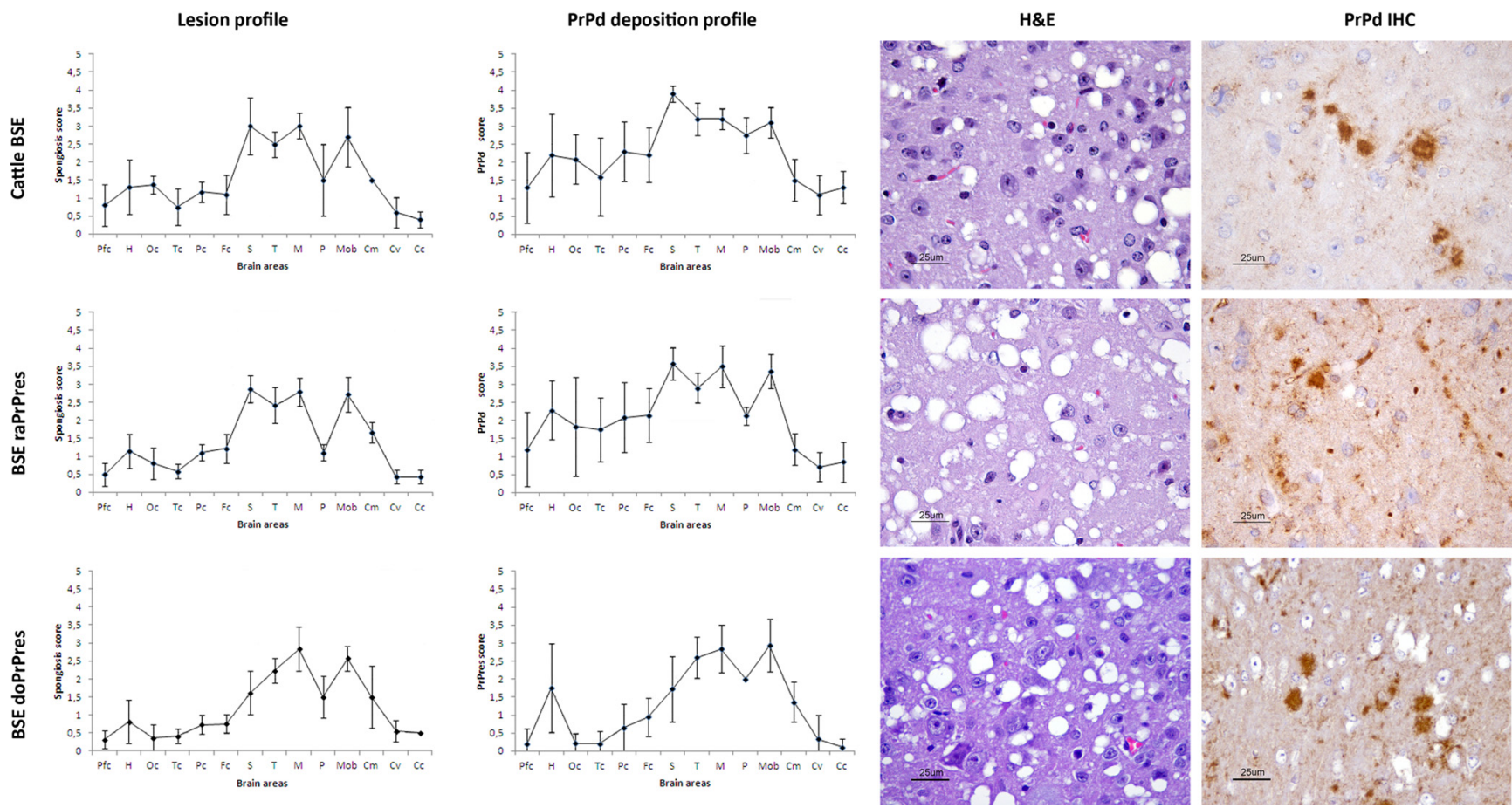

Figure 5. Histopathological characterization of the second passage of cattleBSE, BSE-DoPrP res, and Ra-PrP res in tgBov mice. Lesion profiles and PrP ${ }^{d}$ deposition profiles represent the mean semiquantitative scoring $(0-4$, vertical axis) of the spongiform lesions and the immunohistochemical labeling of PrP d deposits, respectively, against 14 brain regions (horizontal axis: Pfc, piriform cortex; H, hippocampus; 0 , occipital cortex; $\mathrm{Tc}$, temporal cortex; $\mathrm{Pc}$, parietal cortex; $\mathrm{Fc}$, frontal cortex; $\mathrm{S}$, striatum; $\mathrm{T}$, thalamus; $\mathrm{M}$, mesencephalon; $\mathrm{P}$, pons; Mobl, medulla oblongata; $\mathrm{Cm}$, cerebellar nuclei; $(v$, cerebellar vermis; (c, cerebellar hemispheres). Vertical bars indicate the SD of the mean. H\&E, Hematoxylin and eosin staining of the mesencephalon to evaluate the degree of spongiform change; $\mathrm{PrP}^{\mathrm{d}}$ IHC, IHC for PrP ${ }^{d}$ deposits (brown pigment) in the mesencephalon (note the presence of abundant rounded, plake-like PrP ${ }^{d}$ deposits; $6 \mathrm{H} 4 \mathrm{MAb}$ 1:3000). Scale bars, $25 \mu \mathrm{m}$.
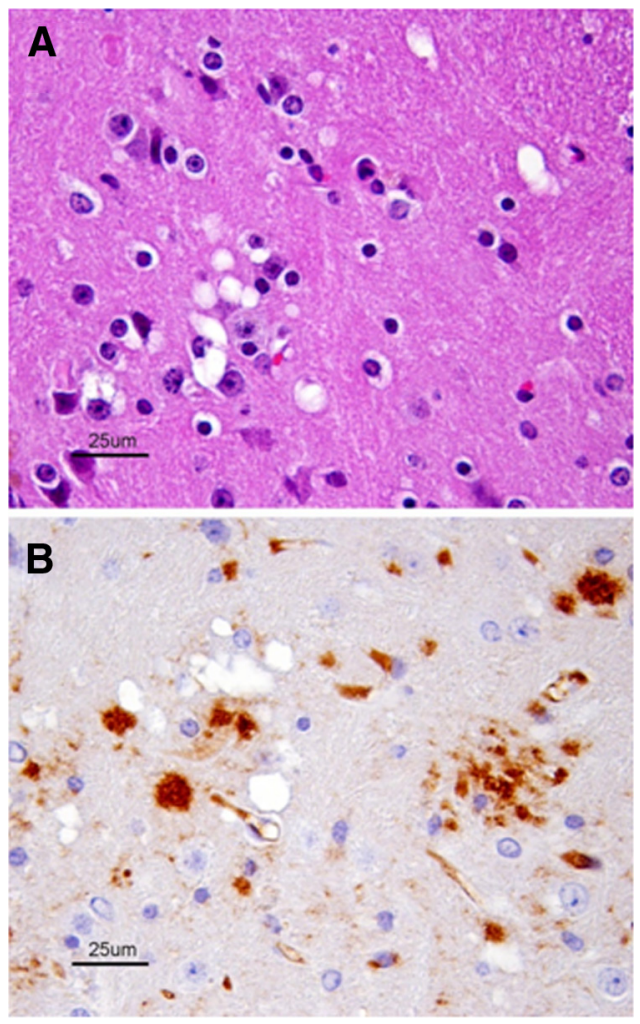

Figure 6. Characterization of BSE-RaPrP res inoculated tgHum mice. $A$, Hematoxylin and eosin staining showing an area of spongiform change in the thalamus. $B$, PrP $^{\mathrm{d}}$ immunohistochemistry (MAb 6H4) of the same area depicts granular PrP ${ }^{d}$ deposits. Scale bars, $25 \mu \mathrm{m}$. Samples were digested with $40 \mu \mathrm{g} / \mathrm{ml}$ PK and analyzed using monoclonal antibody $6 \mathrm{H} 4$.
Table 2. Attack rates and survival times of inoculated tgHum mice

\begin{tabular}{lll}
\hline & First passage & \\
\cline { 2 - 3 } & Attack rate & Survival times (dpi) \\
\hline Cattle BSE & $0 / 9$ & $203,209,234,238,247,271,468,695,797$ \\
BSE-RaPrP res & $2 / 9$ & $170,219,306,327,371,496,560,699,705$ \\
BSE-DoPrP res & $0 / 6$ & $271,549,677,748,818,853$ \\
Healthy brain & $0 / 6$ & $370,428,463,625,692,693$ \\
\hline
\end{tabular}

In bold, the two positive animals' survival time. The remaining data are survival times in dpi (i.e., days between inoculation and sacrifice).

predicted by the in vitro experiments (once initially converted, BSE-DoPrP ${ }^{\text {res }}$ and BSE-RaPrP ${ }^{\text {res }}$ easily amplified further dog and rabbit normal brain homogenates in vitro), both rabbit and dog adapted BSE efficiently infected $\operatorname{tgBov}$ mice with attack rates of $100 \%$. Initially the incubation period was slightly longer for both inocula than that of cattle BSE, probably due to a lack of adaptation of the in vitro generated prions to the new host (bovine) prion. However, on second passage the incubation periods were significantly shortened. Interestingly the behavior of BSEDoPrP ${ }^{\text {res }}$ was similar to that observed in sheep BSE where the biochemical, lesion, and immunohistochemical features were unchanged but with a reduction in the incubation period (Espinosa et al., 2007). The neuropathology and molecular signature of $\mathrm{PrP}^{\text {res }}$ found in $\operatorname{tgBov}$ mice showed no significant differences between cattle BSE and the two in vitro-generated prions, suggesting that the strain features had not changed upon passage through rabbit and dog brain homogenates.

The data shown here prove that the difficulties found in misfolding certain species of $\mathrm{PrP}^{\mathrm{C}}$ molecules do not imply a loss of the pathobiological features encoded in the BSE structure. Compared with cat $\operatorname{PrP}^{\mathrm{C}}$ (data not shown), $\operatorname{dog} \operatorname{PrP}$ was tremendously 
difficult to misfold in vitro. It could only be converted when a relatively large dose of BSE prion was used as seed. However, the similarity of dog PrP primary sequence, differing principally in just three residues (positions: 163, 181, and 189) with cat PrP (Lysek et al., 2005; Stewart et al., 2012), would predict a similar behavior to feline spongiform encephalopathy (FSE). In fact, FSE was one of the first nonbovine prions shown to maintain BSE strain features (Lezmi et al., 2006). Accordingly, once the bovinecanine barrier was surpassed, BSE pathobiological features remained stable in BSE-DoPrP ${ }^{\text {res }}$.

However, the results obtained with BSE cannot be used to predict the behavior of other prion strains when adapted to these species in vivo or in vitro. Thus, instead of a species transmission barrier a strain transmission barrier should be considered as suggested by Scott and coworkers (Scott et al., 2005). Prion strains might be classified according to their ability to transmit to different species and also in relation to their adaptability to new hosts and their permissiveness to change. Therefore, BSE would be a strain with a low (or null) permissiveness to change and yet high adaptability to different environments. As such, the zoonotic behavior of BSE toward humans can be predicted regardless of the host infected with the BSE prion. Any species derivation of BSE, be it rabbit-BSE, dog-BSE, or any other version, is likely to encode a structure capable of misfolding human $\operatorname{PrP}^{\mathrm{C}}$. Second passage experiments in transgenic mice expressing human $\operatorname{PrP}$ (Tg340 mice) would have been useful to determine whether silent infection was present in mice inoculated with cattle BSE and BSEDoPrP ${ }^{\text {res }}$ which seems to be a plausible assumption according to experiments published in this model (Padilla et al., 2011).

Our in vitro and in vivo results predict that, hypothetically, if BSE infected canids and leporids (considered, so far, prion resistant) it would maintain its pathobiological features; including zoonotic potential. This is particularly relevant with respect to rabbit amplified BSE as rabbits are eaten by humans. In conclusion, it is strongly recommended that no mammalian species be fed with animal protein potentially contaminated with BSE to prevent a new epizootic and zoonosis of unknown consequences.

Given the difficulties of performing infectivity studies in many natural hosts (without previous in vitro replication), transgenic mice have been generated expressing rabbit and dog PRNP gene which have been inoculated with cattle BSE, among other strains of interest, to test the in vivo susceptibility of these PRNP sequences. In addition, a detailed study of the primary amino acid sequences of bovine PrP compared with rabbit and dog PrP, focusing on the structural peculiarities of each amino acid change, is ongoing to explain the different $\operatorname{PrP}^{\mathrm{C}}$ to $\operatorname{PrP}^{\mathrm{d}}$ conversion abilities of each species.

\section{References}

Aldhous P (1990) BSE: spongiform encephalopathy found in cat. Nature 345:194. CrossRef Medline

Barlow RM, Rennie JC (1976) The fate of ME7 scrapie infection in rats, guinea-pigs and rabbits. Res Vet Sci 21:110-111. Medline

Barria MA, Telling GC, Gambetti P, Mastrianni JA, Soto C (2011) Generation of a new form of human $\operatorname{Pr} \mathrm{P}(\mathrm{Sc})$ in vitro by interspecies transmission from cervid prions. J Biol Chem 286:7490-7495. CrossRef Medline

Bellworthy SJ, Dexter G, Stack M, Chaplin M, Hawkins SA, Simmons MM, Jeffrey M, Martin S, Gonzalez L, Martin S, Hill P (2008) Oral transmission of BSE to VRQ/VRQ sheep in an experimental flock. Vet Rec 162: 130-131. CrossRef Medline

Bencsik A, Debeer S, Petit T, Baron T (2009) Possible case of maternal transmission of feline spongiform encephalopathy in a captive cheetah. PLoS One 4:e6929. CrossRef Medline

Béringue V, Herzog L, Reine F, Le Dur A, Casalone C, Vilotte JL, Laude H
(2008) Transmission of atypical bovine prions to mice transgenic for human prion protein. Emerg Infect Dis 14:1898-1901. CrossRef Medline

Biacabe AG, Laplanche JL, Ryder S, Baron T (2004) Distinct molecular phenotypes in bovine prion diseases. EMBO Rep 5:110-115. CrossRef Medline

Bruce ME, Will RG, Ironside JW, McConnell I, Drummond D, Suttie A, McCardle L, Chree A, Hope J, Birkett C, Cousens S, Fraser H, Bostock CJ (1997) Transmissions to mice indicate that "new variant" CJD is caused by the BSE agent. Nature 389:498-501. CrossRef Medline

Castilla J, Gutiérrez-Adán A, Brun A, Pintado B, Ramírez MA, Parra B, Doyle D, Rogers M, Salguero FJ, Sánchez C, Sanchez-Vizcaíno JM, Torres JM (2003) Early detection of PrPres in BSE-infected bovine PrP transgenic mice. Arch Virol 148:677-691. CrossRef Medline

Castilla J, Gutiérrez-Adán A, Brun A, Doyle D, Pintado B, Ramírez MA, Salguero FJ, Parra B, Segundo FD, Sánchez-Vizcaíno JM, Rogers M, Torres JM (2004) Subclinical bovine spongiform encephalopathy infection in transgenic mice expressing porcine prion protein. J Neurosci 24:50635069. CrossRef Medline

Castilla J, Saá P, Hetz C, Soto C (2005a) In vitro generation of infectious scrapie prions. Cell 121:195-206. CrossRef Medline

Castilla J, Brun A, Díaz-San Segundo F, Salguero FJ, Gutiérrez-Adán A, Pintado B, Ramírez MA, del Riego L, Torres JM (2005b) Vertical transmission of bovine spongiform encephalopathy prions evaluated in a transgenic mouse model. J Virol 79:8665-8668. CrossRef Medline

Castilla J, Saá P, Morales R, Abid K, Maundrell K, Soto C (2006) Protein misfolding cyclic amplification for diagnosis and prion propagation studies. Methods Enzymol 412:3-21. CrossRef Medline

Castilla J, Gonzalez-Romero D, Saá P, Morales R, De Castro J, Soto C (2008) Crossing the species barrier by $\operatorname{Pr} \mathrm{P}(\mathrm{Sc})$ replication in vitro generates unique infectious prions. Cell 134:757-768. CrossRef Medline

Chianini F, Fernández-Borges N, Vidal E, Gibbard L, Pintado B, de Castro J, Priola SA, Hamilton S, Eaton SL, Finlayson J, Pang Y, Steele P, Reid HW, Dagleish MP, Castilla J (2012) Rabbits are not resistant to prion infection. Proc Natl Acad Sci U S A 109:5080-5085. CrossRef Medline

Collinge J, Sidle KC, Meads J, Ironside J, Hill AF (1996) Molecular analysis of prion strain variation and the aetiology of "new variant" CJD. Nature 383:685-690. CrossRef Medline

Eiden M, Hoffmann C, Balkema-Buschmann A, Müller M, Baumgartner K, Groschup MH (2010) Biochemical and immunohistochemical characterization of feline spongiform encephalopathy in a German captive cheetah. J Gen Virol 91:2874-2883. CrossRef Medline

Eloit M, Adjou K, Coulpier M, Fontaine JJ, Hamel R, Lilin T, Messiaen S, Andreoletti O, Baron T, Bencsik A, Biacabe AG, Beringue V, Laude H, Le Dur A, Vilotte JL, Comoy E, Deslys JP, Grassi J, Simon S, Lantier F, Sarradin P (2005) BSE agent signatures in a goat. Vet Rec 156:523-524. CrossRef Medline

Espinosa JC, Andréoletti O, Castilla J, Herva ME, Morales M, Alamillo E, San-Segundo FD, Lacroux C, Lugan S, Salguero FJ, Langeveld J, Torres JM (2007) Sheep-passaged bovine spongiform encephalopathy agent exhibits altered pathobiological properties in bovine-PrP transgenic mice. J Virol 81:835-843. CrossRef Medline

Fernández-Borges N, Castilla J (2010) PMCA: a decade of in vitro prion replication. Curr Chem Biol 4:200-207. CrossRef

Fernández-Borges N, de Castro J, Castilla J (2009) In vitro studies of the transmission barrier. Prion 3:220-223. CrossRef Medline

Foster JD, Hope J, Fraser H (1993) Transmission of bovine spongiform encephalopathy to sheep and goats. Vet Rec 133:339-341. CrossRef Medline

Fraser H, McConnell I, Wells GA, Dawson M (1988) Transmission of bovine spongiform encephalopathy to mice. Vet Rec 123:472. CrossRef Medline

Gibbs CJ Jr, Gajdusek DC (1973) Experimental subacute spongiform virus encephalopathies in primates and other laboratory animals. Science 182: 67-68. CrossRef Medline

Green KM, Castilla J, Seward TS, Napier DL, Jewell JE, Soto C, Telling GC (2008) Accelerated high fidelity prion amplification within and across prion species barriers. PLoS Pathog 4:e1000139. CrossRef Medline

Hill AF, Desbruslais M, Joiner S, Sidle KC, Gowland I, Collinge J, Doey LJ, Lantos P (1997) The same prion strain causes vCJD and BSE. Nature 389:448-450,526. CrossRef Medline

Kirkwood JK, Cunningham AA (1994) Epidemiological observations on spongiform encephalopathies in captive wild animals in the British Isles. Vet Rec 135:296-303. CrossRef Medline 
Konold T, Spiropoulos J, Chaplin MJ, Thorne L, Spencer YI, Wells GA, Hawkins SA (2009) Transmissibility studies of vacuolar changes in the rostral colliculus of pigs. BMC Vet Res 5:35. CrossRef Medline

Kurt TD, Seelig DM, Schneider JR, Johnson CJ, Telling GC, Heisey DM, Hoover EA (2011) Alteration of the chronic wasting disease species barrier by in vitro prion amplification. J Virol 85:8528-8537. CrossRef Medline

Lasmézas CI, Deslys JP, Demaimay R, Adjou KT, Lamoury F, Dormont D, Robain O, Ironside J, Hauw JJ (1996) BSE transmission to macaques. Nature 381:743-744. CrossRef Medline

Lezmi S, Bencsik A, Monks E, Petit T, Baron T (2003) First case of feline spongiform encephalopathy in a captive cheetah born in France: $\operatorname{PrP}(\mathrm{sc})$ analysis in various tissues revealed unexpected targeting of kidney and adrenal gland. Histochem Cell Biol 119:415-422. CrossRef Medline

Lezmi S, Bencsik A, Baron T (2006) PET-blot analysis contributes to BSE strain recognition in C57BL/6 mice. J Histochem Cytochem 54:10871094. CrossRef Medline

Lysek DA, Schorn C, Nivon LG, Esteve-Moya V, Christen B, Calzolai L, von Schroetter C, Fiorito F, Herrmann T, Güntert P, Wuthrich K (2005) Prion protein NMR structures of cats, dogs, pigs, and sheep. Proc Natl Acad Sci U S A 102:640-645. CrossRef Medline

Padilla D, Béringue V, Espinosa JC, Andreoletti O, Jaumain E, Reine F, Herzog L, Gutierrez-Adan A, Pintado B, Laude H, Torres JM (2011) Sheep and goat BSE propagate more efficiently than cattle BSE in human PrP transgenic mice. PLoS Pathog 7:e1001319. CrossRef Medline

Polymenidou M, Trusheim H, Stallmach L, Moos R, Julius C, Miele G, LenzBauer C, Aguzzi A (2008) Canine MDCK cell lines are refractory to infection with human and mouse prions. Vaccine 26:2601-2614. CrossRef Medline

Saá P, Castilla J, Soto C (2005) Cyclic amplification of protein misfolding and aggregation. Methods Mol Biol 299:53-65. Medline

Saá P, Castilla J, Soto C (2006) Ultra-efficient replication of infectious prions by automated protein misfolding cyclic amplification. J Biol Chem 281:35245-35252. CrossRef Medline

Saborio GP, Permanne B, Soto C (2001) Sensitive detection of pathological prion protein by cyclic amplification of protein misfolding. Nature 411: 810-813. CrossRef Medline

Safar JG, Giles K, Lessard P, Letessier F, Patel S, Serban A, Dearmond SJ, Prusiner SB (2011) Conserved properties of human and bovine prion strains on transmission to guinea pigs. Lab Invest 91:1326-1336. CrossRef Medline

Scott MR, Peretz D, Nguyen HO, Dearmond SJ, Prusiner SB (2005) Transmission barriers for bovine, ovine, and human prions in transgenic mice. J Virol 79:5259-5271. CrossRef Medline

Scott M, Foster D, Mirenda C, Serban D, Coufal F, Wälchli M, Torchia M, Groth D, Carlson G, DeArmond SJ, Westaway D, Prusiner SB (1989) Transgenic mice expressing hamster prion protein produce species- specific scrapie infectivity and amyloid plaques. Cell 59:847-857. CrossRef Medline

Sigurdson CJ, Manco G, Schwarz P, Liberski P, Hoover EA, Hornemann S, Polymenidou M, Miller MW, Glatzel M, Aguzzi A (2006) Strain fidelity of chronic wasting disease upon murine adaptation. J Virol 80:1230312311. CrossRef Medline

Sisó S, Ordóñez M, Cordón I, Vidal E, Pumarola M (2004) Distribution of PrPres in the brains of BSE-affected cows detected by active surveillance in Catalonia, Spain. Vet Rec 155:524-525. CrossRef Medline

Stack MJ, Chaplin MJ, Clark J (2002) Differentiation of prion protein glycoforms from naturally occurring sheep scrapie, sheep-passaged scrapie strains (CH1641 and SSBP1), bovine spongiform encephalopathy (BSE) cases and Romney and Cheviot breed sheep experimentally inoculated with BSE using two monoclonal antibodies. Acta Neuropathol 104:279_ 286. CrossRef Medline

Stewart P, Campbell L, Skogtvedt S, Griffin KA, Arnemo JM, Tryland M, Girling S, Miller MW, Tranulis MA, Goldmann W (2012) Genetic predictions of prion disease susceptibility in carnivore species based on variability of the prion gene coding region. PLoS One 7:e50623. CrossRef Medline

Vidal E, Marquez M, Ordonez M, Raeber AJ, Struckmeyer T, Oesch B, Siso S, Pumarola M (2005) Comparative study of the PrPBSE distribution in brains from BSE field cases using rapid tests. J Virol Methods 127:24-32. CrossRef Medline

Vorberg I, Groschup MH, Pfaff E, Priola SA (2003) Multiple amino acid residues within the rabbit prion protein inhibit formation of its abnormal isoform. J Virol 77:2003-2009. CrossRef Medline

Wells GA, Wilesmith JW (1995) The neuropathology and epidemiology of bovine spongiform encephalopathy. Brain Pathol 5:91-103. CrossRef Medline

Wells GA, Scott AC, Johnson CT, Gunning RF, Hancock RD, Jeffrey M, Dawson M, Bradley R (1987) A novel progressive spongiform encephalopathy in cattle. Vet Rec 121:419-420. CrossRef Medline

Wells GA, Hawkins SA, Austin AR, Ryder SJ, Done SH, Green RB, Dexter I, Dawson M, Kimberlin RH (2003) Studies of the transmissibility of the agent of bovine spongiform encephalopathy to pigs. J Gen Virol 84:10211031. CrossRef Medline

Willoughby K, Kelly DF, Lyon DG, Wells GA (1992) Spongiform encephalopathy in a captive puma (Felis concolor). Vet Rec 131:431-434. CrossRef Medline

Wyatt JM, Pearson GR, Smerdon TN, Gruffydd-Jones TJ, Wells GA, Wilesmith JW (1991) Naturally occurring scrapie-like spongiform encephalopathy in five domestic cats. Vet Rec 129:233-236. CrossRef Medline

Yoshioka M, Imamura M, Okada H, Shimozaki N, Murayama Y, Yokoyama T, Mohri S (2011) Sc237 hamster PrPSc and Sc237-derived mouse PrPSc generated by interspecies in vitro amplification exhibit distinct pathological and biochemical properties in tga20 transgenic mice. Microbiol Immunol 55:331-340. CrossRef Medline 